\title{
Identification of high surge pressure in LNG loading lines system and mitigation strategy
}

\author{
Noor Arnida Abdul Talip ${ }^{1}$, Siti Farhana M Shaari² Fadzrul Izwan Muhd Ali³, \\ ${ }^{1,3}$ Group Technical Solutions (GTS),PETRONAS ${ }^{2}$ Malaysia Liquefied Natural Gas (MLNG), PETRONAS
}

\begin{abstract}
This paper presents the criticality of surge simulation and analysis to establish if surge (pressure exceeding pipe design limit) is present upon ESD activation case during loading of LNG from loading lines to carrier.

Keywords: Pressure Surges, Cavitation, Vapour Bubbles Collapse, Emergency Shudtown, Loading Lines.
\end{abstract}

\section{Introduction}

Proper design of LNG loading lines (Figure 1) and verification of ESD interlock systems are critical in ensuring overall safety of the LNG facility. During an emergency, ESD interlock is activated with ESD valves closure initiated simultaneously with all loading pumps trip and the kickback valves open. During the ESD valves closure, the pipeline can be exposed to a risk of high surge pressures exerted onto the wall. A pressure surge or liquid hammering phenomenon in piping systems can be caused by a fluid in motion forced to stop or change direction suddenly (rapid momentum change) and also due to cavitation effect. Cavitation is caused by the formation and instantaneous collapse of vapour bubbles. The collapsing bubbles exert severe localized impact forces that can result in pressure surges.

\begin{abstract}
Understanding the challenges posed by a potential safety risk due to surge occurrences may be the first step in incorporating HSE prior to the construction of a new facility (e.g a new tiein to the LNG loading line) in an LNG asset. A PIPENET simulation model is developed from an iCON base case model previously used to verify Flowmaster prediction of the surge pressure magnitude and location. The PIPENET model is then benchmarked with actual performance test run (PTR) data by tuning pipe friction factor and matching the total LNG loading flowrate irrespective of number of pumps running. The verified model was subsequently used to assess the adequacy of the mitigation actions proposed to minimize the effect of cavitation and very high surge pressure during ESD activation.
\end{abstract}

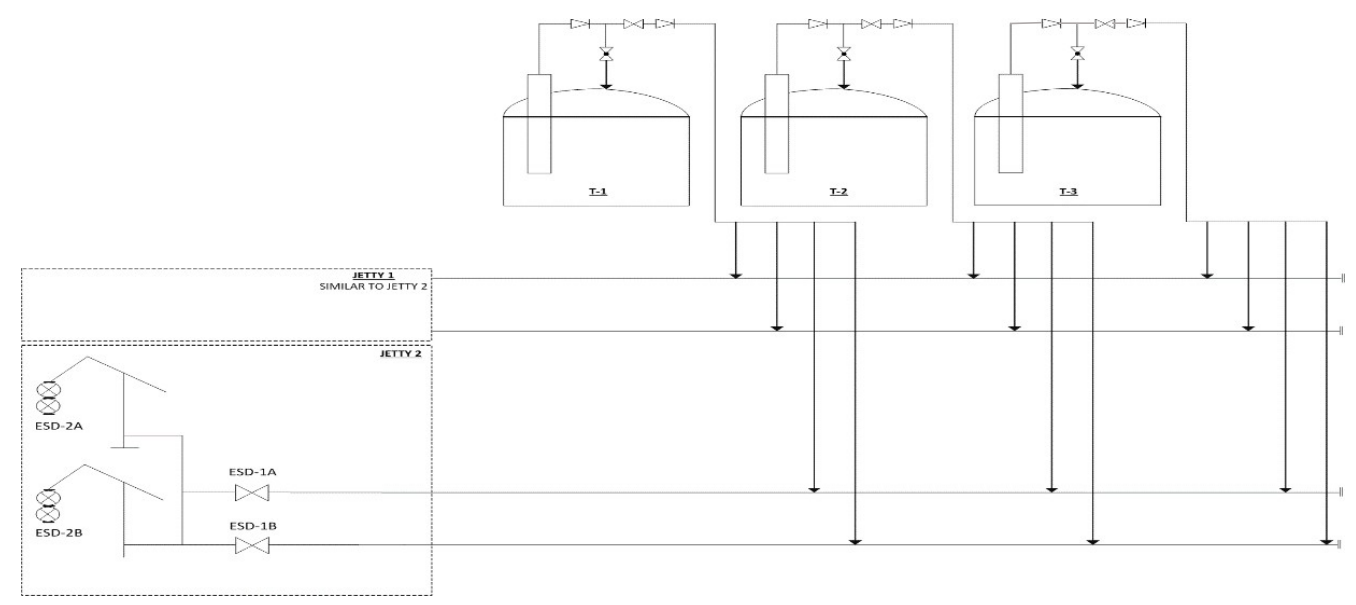

Fig. 1. General Schematic of LNG Loading System from Tanks to LNG Loading Arms at Jetty

\footnotetext{
*Authors: arnida talip@petronas.com.my, sitifarhana@petronas.com.my, fadzrulizwan@petronas.com.my
} 


\section{Methodology}

This study focused on surge analysis using an appropriate tool, PIPENET to determine any exposure to high surge pressure and transient forces throughout the transfer lines plus mitigation plans to be implemented if necessary. Figure 2 below summarizes the approach that was employed for the study.

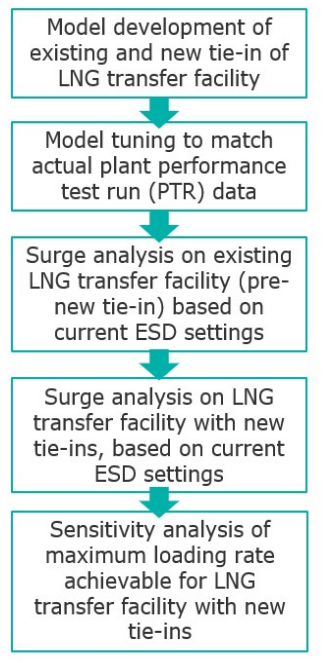

- Utilized surge analysis tool, PIPENET transient software

- Point by point pressure node matching

Current ESD settings has incorporated high surge mitigation measures (prolonging ESD valve stroke valves)

- Verification on the adequacy of current ESD settings to handle potential surge issues

Potential increment in LNG loading.
This study considered loading from three LNG storage tanks which are furthest from berth as longer distances are anticipated to lead to higher surge pressures. The PIPENET schematic overview of the scope for this study is shown below. The study battery limit is;

i. Pump at LNG

tanks up until the

ii. Loading

arms, and iii. ESD

valve at new tie-in

facility.

Fig. 2. High pressure surge study approach

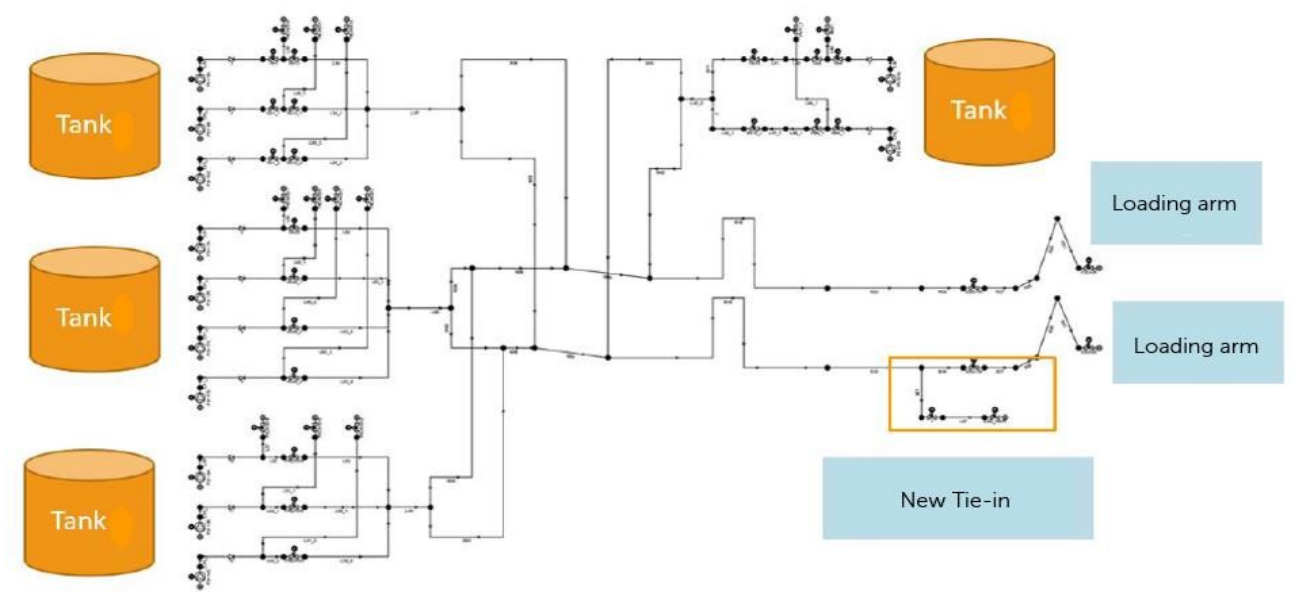

Fig.3. PIPENET Model Schematidiagram

* Authors: arnida talip@petronas.com.my, sitifarhana@petronas.com.my, fadzrulizwan@petronas.com.my 
The base case PIPENET model has been tuned to match the actual Performance Test Run (PTR) result. The steady state pressure profiles are within $5 \%$ difference. Using the steady state pressure profile as a base, subsequent surge analysis is performed. The considered case scenarios are as follows:

Case 1: ESD-2 is initiated with loading operation to jetty (existing facility only) and subsequent ESD actions takes place by sequences (i.e. kickback valves immediately open, loading pumps tripped and shutdown valves closed).

Case 2: ESD-2 and ESD of new tie-in facility are initiated with loading operation to jetty and new tie-in facility, and subsequent ESD actions takes place by sequences (i.e. kickback valves immediately open, loading pumps tripped and shutdown valves closed).

Case 3: Maximum loading flowrate achievable with safe ESD actions in place.

\section{Result and Discussion}

The result for each case scenario is summarized as below. The sequence of activity for each case is shown accordingly in the graphs.

Case 1: ESD-2 is initiated with loading operation to jetty (existing facility only) and subsequent ESD actions takes place by sequences (i.e. kickback valves immediately open, loading pumps tripped and shutdown valves closed).

As can be observed in Figure 4, system pressure at ESD-1 valve is seen as steady at about $21 \%$ from design pressure limit during initial simulation and then spikes momentarily up to $84 \%$ at $\mathrm{T}=15 \mathrm{~s}$ when ESD-2 valve is fully closed. At the same time $\mathrm{T}=15 \mathrm{~s}$, all respective kickback valves are set to full open. Pressure at the upstream of ESD-1 valve then gradually reduces to the final steady state pressure (blue line in graph) indicating that all system pressure in the pipe segments has been released via the kickback valves. Minimal cavitation formation is seen at the upstream of ESD-1 valve (pink line in the graph) which occurs temporarily once the system pressure drops to LNG vapor pressure.

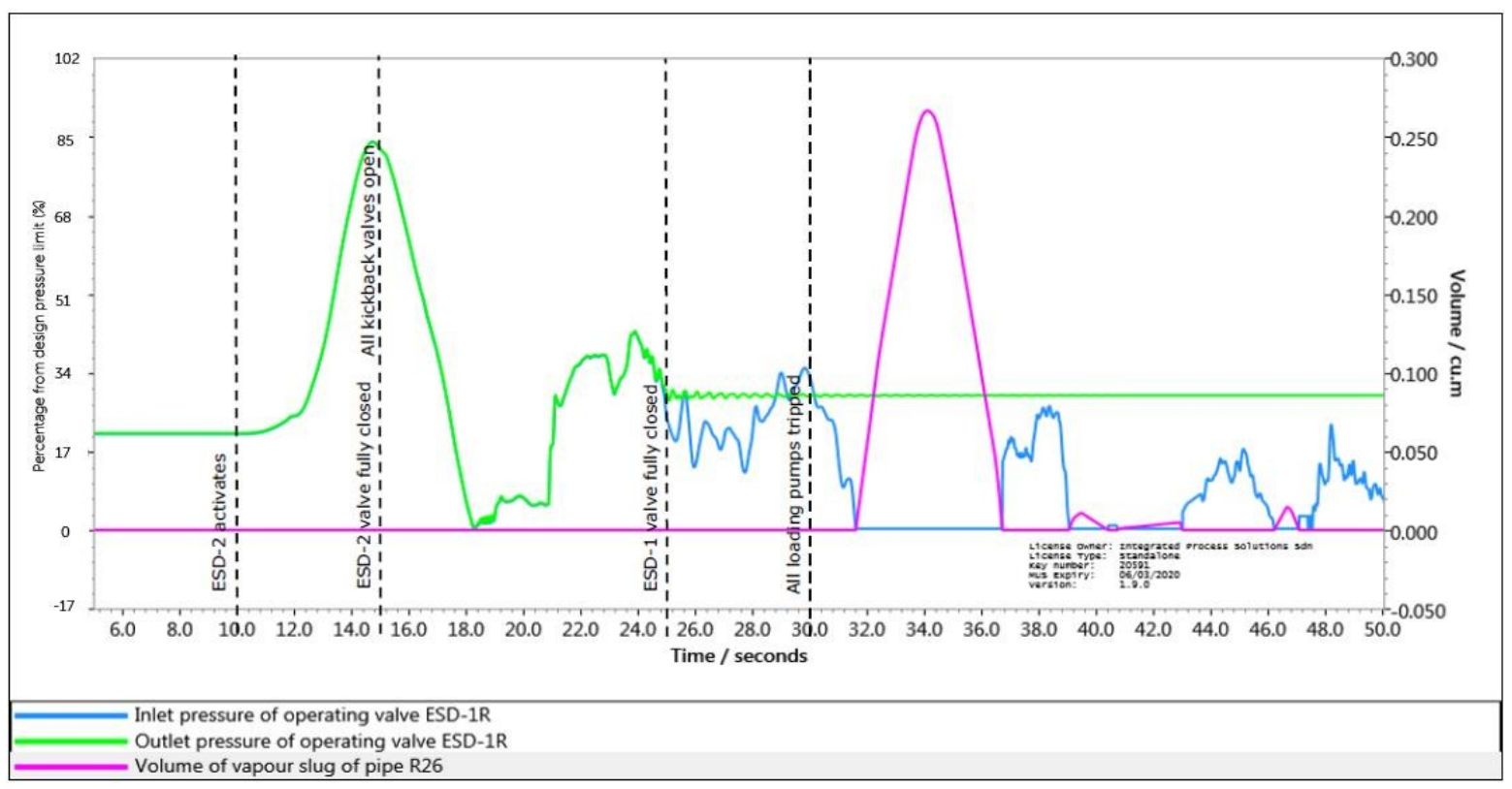

Fig. 4. Pressure Profile at Upstream and Downstream of ESD-1 Valve

Meanwhile as shown in Figure 5, the highest surge pressure is about $88 \%$ from the design pressure limit is seen to occur at the upstream of ESD-2 for this case. This surge pressure is still below the piping design limit and occurs at $\mathrm{T}=14.5 \mathrm{~s}$ when ESD-2 valve is just about to fully closed. The pressure then vacillates for a few seconds before they settle at the final steady state pressure of about $28 \%$ from the design pressure limit. Loading pumps are still running at this moment, and only tripped at $\mathrm{T}=30 \mathrm{~s}$.

\footnotetext{
*Authors: arnida talip@petronas.com.my, sitifarhana@petronas.com.my, fadzrulizwan@petronas.com.my
} 


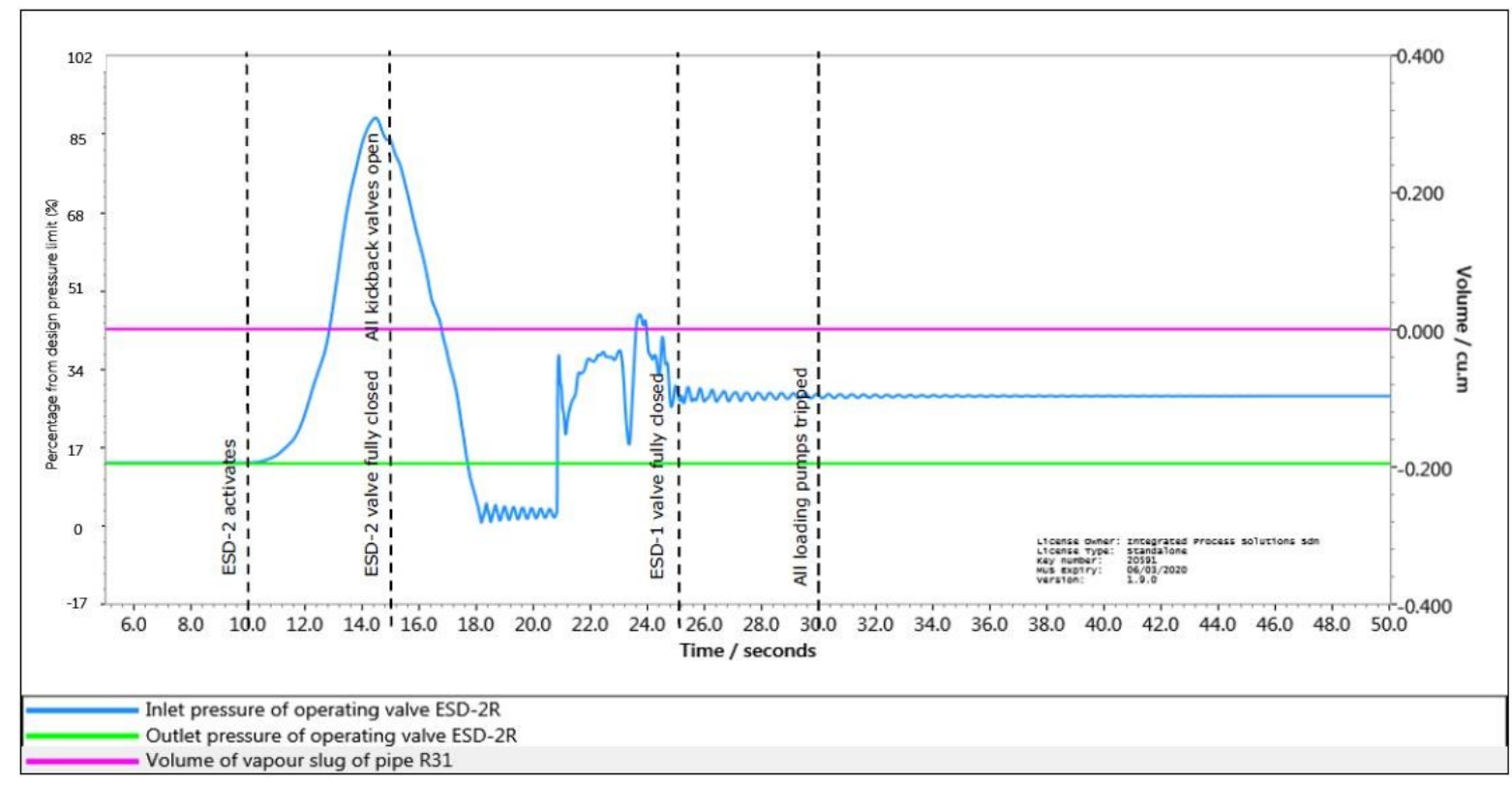

Fig. 5. Pressure Profile at Upstream and Downstream of ESD-2 Valve

Pressure surges more than 50\% from design pressure limit are also seen to occur at few other locations in this simulation case. Refer Figure 6 for the locations and percentage of surge pressure from design limit in schematic diagram.

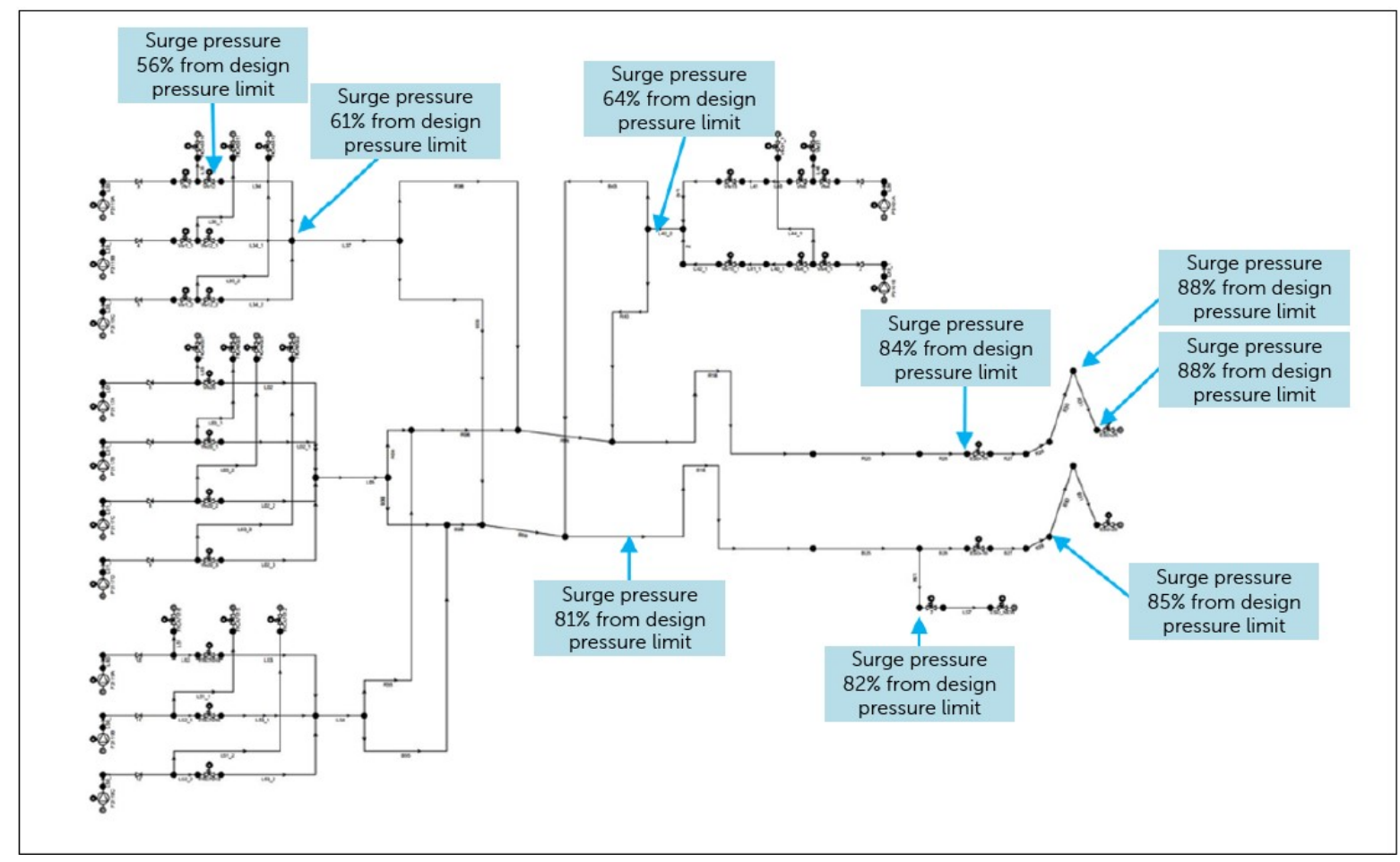

Fig. 6. Pressure Surges Location at LNG Tanks and Jetty Facility

Case 2: ESD-2 and ESD of new tie-in facility are initiated with loading operation to jetty and new tie-in facility, and subsequent ESD actions takes place by sequences (i.e. kickback valves immediately open, loading pumps tripped and shutdown valves closed).

Case 2 is performed to review the impact of ESD-2 and ESDnew tie-in facility activation to surge pressures, while loading

\footnotetext{
*Authors: arnida talip@petronas.com.my, $\underline{\text { sitifarhana@petronas.com.my, fadzrulizwan@petronas.com.my }}$
} 
operation happens simultaneously to new tie-in facility and to ship at jetty. Findings for this case:

a) The pressure surge for all scenarios are less than piping design limit and poses no threat to the system

b) Pressure surges higher at upstream of ESD-1 valve (about 1 bar difference) for scenario where both ESD-new tie-in facility and ESD-2 initiated simultaneously (as compared to ESD-2 initiation only) c) Pressure surge is seen higher for the scenario where ESD-new tie-in facility's valve stroke/closing time is 5 seconds as compared to 15 seconds.
Case 3: Maximum loading flowrate achievable with safe ESD actions in place

Case 3 is simulated to determine the maximum loading flowrate achievable with safe ESD actions in place to handle surge pressures. The ESD-2 setting is used as the basis of this case. Findings for this case:

a) Total maximum flowrate (from LNG tanks) with acceptable surge pressures:

\begin{tabular}{|l|c|c|}
\hline Scenario & $\begin{array}{c}\text { Percentage Increment in } \\
\text { Loading Flowrate }\end{array}$ & $\begin{array}{c}\text { Max Surge Pressure (in } \\
\text { percentage from design limit) }\end{array}$ \\
\hline $\begin{array}{l}\text { Loading to berth (existing } \\
\text { facility only) }\end{array}$ & $17.16 \%$ & $91.2 \%$ \\
\hline $\begin{array}{l}\text { Loading to berth and new tiein } \\
\text { facility }\end{array}$ & $20.6 \%$ & $90.6 \%$ \\
\hline
\end{tabular}

For the scenarios mentioned above, the loading flowrate is fed by pumps from the three furthest tanks from berth.

b) Allowable flowrate is higher for the scenario where loading operation occurs simultaneously to berth and new tie-in facility (as compared to loading to berth only) since the additional new tie-in pipe section inventory would allow the surge to ripple away thus taking away some of the force to the ESD-2 valve.

\section{Conclusion}

The findings based on surge simulation and analysis confirm that high pressure surges are credible to occur at multiple locations at the LNG loading facility during ESD activation scenario. It is crucial to identify the potential locations and also the magnitude of the high surge to ensure that it is acceptable and below design pressure limit. This is to prevent loss of primary containment (LOPC) by ensuring the ESD settings are sufficient to handle possible pressure surges in case of ESD activates.

For a scenario where the maximum pressure surges do not exceed the pipeline design limit and covering all the cases, there is a potential to increase the loading flowrate to a certain extent. However, it is still necessary to consider limiting the loading flowrate around 5 to $10 \%$ below the maximum simulated;

i) to account for uncertainties (and deviation in simulated parameters than the actual condition, i.e. LNG densities, tanker/ship pressure, etc), and ii) to ensure that the potential surge pressure does not hit close to the maximum surge pressures.

\section{References}

[1] R.M.F. Raja M Hanif, A.T. Noor Arnida, "LNG loading lines high surge verification study" unpublished.

[2] "Operational Testing Report for Tank X and New Jetty Piping and Associated Facilities”, Doc No. T-

12.223 .472

\footnotetext{
*Authors: arnida talip@petronas.com.my, sitifarhana@petronas.com.my, fadzrulizwan@petronas.com.my
} 